\title{
Framing Microgrid Design from a Business and Information Systems Engineering Perspective
}

\author{
Thomas Sachs • Anna Gründler • Milos Rusic • Gilbert Fridgen
}

Received: 13 June 2016/Accepted: 18 September 2018/Published online: 11 January 2019

(C) The Author(s) 2019

\begin{abstract}
Microgrids are decentralized distribution networks that integrate distributed energy resources and balance energy generation and loads locally. The introduction of microgrids can help overcome the challenges of global energy systems. Despite this potential, the information systems domain has seen limited research on microgrids. This paper synthesizes research on elements of microgrids for electric energy. Interviewed experts maintain that technological microgrid solutions have been solidly developed; nevertheless, the lack of economic and business consideration is stalling their deployment. The authors argue that business and information systems engineering research can provide integrated perspectives that connect technology and markets. Consequently, the authors derive a framework from an extensive interdisciplinary literature review that structures the academic state of the art on
\end{abstract}

Accepted after four revisions by Jelena Zdravkovic.

Electronic supplementary material The online version of this article (https://doi.org/10.1007/s12599-018-00573-0) contains supplementary material, which is available to authorized users.

T. Sachs · G. Fridgen $(\bowtie)$

Fraunhofer FIT - Project Group Business \& Information

Systems Engineering, University of Bayreuth, 95440 Bayreuth,

Germany

e-mail: gilbert.fridgen@fit.fraunhofer.de

T. Sachs

e-mail: thomas.sachs@uni-bayreuth.de

\author{
A. Gründler · M. Rusic \\ Research Center Finance \& Information Management, \\ University of Augsburg, 86135 Augsburg, Germany \\ e-mail: anna.gruendler@fim-rc.de \\ M. Rusic \\ e-mail: milos.rusic@fim-rc.de
}

microgrid design and could guide associated information systems research. The framework comprises four layers: energy technology and infrastructure, information and communication infrastructure, application systems, and governance. The authors evaluate the framework in interviews with 15 experts from industry and three from academia. Their feedback allows to iteratively refine the framework and point out research directions on microgrids in business and information systems engineering.

Keywords Microgrid · Renewable energy sources · Framework · Literature review · Research agenda · Green IS · Energy informatics

\section{Motivation and Research Questions}

In a global Delphi study on future trends in energy systems, $64 \%$ of 350 experts from around the world argued that "by 2040 the energy supply system will be structured in a cellular way: interconnected cells and 'islands' of the size of a city or medium-sized region will generate their energy from solar power, wind power, storage units and a minor share of conventional reserves" (BDEW et al. 2016). In this future energy system, microgrids will play an important role. A microgrid is a small, decentralized distribution network comprising electricity generation, loads, and storage devices. It presents itself to the main power grid as a single controllable load that can also operate in islanded (self-sufficient) mode (Liang and Zhuang 2014). According to Hossain et al. (2014), microgrids are "one of the most practical solutions for green and reliable power."

Microgrids' ability to mitigate energy systems' challenges, such as integrating renewable energies (Hatziargyriou et al. 2007), simplifying demand side management 
(Allard et al. 2013), reducing electricity costs (Brandt et al. 2014), and electrifying rural areas (Mandelli et al. 2016), explain their rise. In Germany, for example, there is a shift towards renewable energies in the energy policy, called the "Energiewende" (Strunz 2014). The German government started paying subsidies for renewable energy sources (RES) in 2000 to foster this strategy and to ensure that $80 \%$ of the consumed electricity (gross electricity consumption) would come from renewable sources by 2050 (Bundesministerium für Wirtschaft und Energie 2016). By bringing about more decentralized and intermittent generation, this development towards RES affects the low voltage electricity grid profoundly. Concerning connection, transmission capacity, and grid stability, readying the grid for such a high share of intermittent generation units will require substantial investments. Currently, the changes are leading to increasing grid charges, which contribute to rising consumer electricity prices (Paraschiv et al. 2014). Instead of extending the grid to adjust to peaks in the renewable electricity production, decentralized structures could help integrate RES (Hatziargyriou et al. 2007).

So far, the microgrid concept has been well developed from an electro-technical perspective. However, implementing such decentralized energy systems requires an interdisciplinary view and similar efforts to resolve economic, commercial, and technical challenges (Hatziargyriou et al. 2007). The concept will also influence society: $59 \%$ of the experts interviewed for the mentioned Delphi study stated that decentralization might lead to the "emergence of new democratic self-governance structures at the local level" (BDEW et al. 2016). Understanding the potential role of microgrids in our prospective energy system, as well as the economic, commercial, and social implications behind their design and development, has become a pressing issue.

"Microgrid design" means setting up an instance of a microgrid in practice, which requires managerial decisions. Its traditional understanding of engineering in line with solving business problems (Buhl et al. 2012) equips the Business and Information Systems Engineering (BISE) community to advance the business side of microgrid design. Equally, information systems researchers can contribute significantly to the field of microgrids, which are socio-technical constructs with a great need for integrating information systems. Nevertheless, to date, there is only limited research on microgrids in the BISE and information systems (BISE/IS) community. For example, in the Association for Information Systems (AIS) electronic library, only four papers (at the end of 2017) address the topic in detail. Experts expect microgrid systems to be integrated into the future electricity market (BDEW et al. 2016), which requires domain-specific BISE/IS artifacts to approach this topic and to facilitate its emergence.
Microgrids have become a promising area of research, especially for the Green Information Systems and Energy Informatics streams (Brandt et al. 2014).

Our objective is to structure the academic state of the art (SOTA) of microgrid design and to derive research gaps that the BISE/IS community could address, thus to bridge the gap between academia and business practice. We address two research questions (RQ) in this paper:

RQ 1: What framework can structure design options that interdisciplinary literature describes for setting up a microgrid?

RQ 2: To which aspects of the microgrid concept should BISE/IS researchers direct further effort?

\section{Microgrids: Definitions and State of Practice}

The contemporary concept of "smart grids" refers to electricity networks, distribution grids in particular, which are evolving to intelligently integrate the consumption and feed-in behavior of all units connected to them. Smart grids integrate information systems allowing for autonomous or semi-autonomous planning, monitoring, and coordination (e.g., smart metering) to accommodate dynamics, such as a varying generation from intermittent RES. Such distribution grids experience their transformation "from passive to active networks, in the sense that decision-making and control are distributed, and power flows bidirectional" (Schwaegerl and Tao 2014b).

Microgrids have been characterized as forming the "building blocks of smart grids," meaning that their controller and distributed energy resources equip them to either operate as a section of a modern distribution grid or independently from the main grid (Schwaegerl and Tao 2014b). They can, therefore, endure natural disasters or other disturbances in the main grid. Research on microgrids has received "political support and funding around the globe" (Brandt 2016), exemplified by the EU-supported More Microgrids research project, which was the first European research project in this field (Hatziargyriou et al. 2007). The Consortium for Electric Reliability Technology Solutions (CERTS) established a well-known US research and development project on microgrids in 1999. The CERTS microgrid concept was implemented at pilot sites, such as Santa Rita Jail in California (Lasseter et al. 2002). Today, several electrical equipment manufacturers such as Schneider Electric, ABB, and Siemens develop microgrid technologies.

Definitions from CERTS, More Microgrids, and the International Council on Large Electric Systems (CIGRÉ) mention four main characteristics of a microgrid: 
Table 1 Microgrid definitions (authors' highlighting)

\begin{tabular}{ll}
\hline Institution & Definition \\
\hline CERTS Microgrid Concept (2002) & $\begin{array}{l}\text { [A microgrid is] an aggregation of loads and microsources operating as a single system providing both } \\
\text { power and heat. The majority of the microsources must be power electronic based to provide the } \\
\text { required flexibility to insure operation as a single aggregated system. This control flexibility allows the } \\
\text { [microgrid] to present itself to the bulk power system as a single controlled unit that meets local needs } \\
\text { for reliability and security } \\
\text { Microgrids comprise low voltage }(L V) \text { distribution systems with distributed energy resources (micro } \\
\text { turbines, fuel cells, PV, etc.) together with storage devices (flywheels, energy capacitors, and batteries) } \\
\text { and flexible loads. Such systems can be operated in a non-autonomous way, if interconnected to the grid, } \\
\text { or in an autonomous way, if disconnected from the main grid } \\
\text { Microgrids are electricity distribution systems containing loads and distributed energy resources (such } \\
\text { as distributed generators, storage devices, or controllable loads) that can be operated in a controlled, } \\
\text { coordinated way either while connected to the main power network or while islanded }\end{array}$ \\
\hline Marnay et al. 2015) &
\end{tabular}

intelligent control, ability to operate in grid-connected and islanded mode, local aspect, and flexibility (Table 1).

Microgrids are, to some extent, currently established around the world for applications such as critical infrastructures and rural electrification. Autonomous microgrids are mostly found in remote areas, islands, and developing countries. Utility microgrids are the primary use case in China and Europe, where renewable energy is developing rapidly. Romankiewicz et al. (2014) provide an international review and case studies of microgrid programs to date. They refer to programs in Asia (China, Japan, Singapore, South Korea), the EU (Denmark, Germany, Greece), and the Americas (Canada, Chile, US). Additional projects, with a focus on Australia, are mentioned in ABB (2015).

\section{Method}

We follow a qualitative research strategy, comprising inductive and deductive elements, to answer our research questions. We set out with the idea of an interdisciplinary literature review: via argumentative reasoning, we derive a framework that structures the SOTA of microgrid design. We choose this strategy, as various, mainly business, aspects of microgrids still need to be defined, for example, the commercial interaction with centralized resources of electricity generation and transmission (Soshinskaya et al. 2014; Tao et al. 2011). Despite the international examples described above, the number of existing microgrid projects is still limited. We shall, therefore, focus on describing qualitative experience to a greater extent than statistical evidence (Hossain et al. 2014).

By positioning microgrids in the Energy Informatics (EI) area, we endeavor to foster research on microgrid design and deployment. Goebel et al. (2014) encourage "EI researchers with a background in economics and market design (...) [to] help to develop innovative market structures and products that facilitate the market participation of distributed generation, flexible loads, and energy storage." Similarly, Gholami et al. (2016) express the necessity to research Green Information Systems solutions to problems resulting from the shift to intermittent RES: "[this shift] is not just a smart grid problem. It also requires designing new organizational structures." Microgrids are one such prospective market structure. Hence, we develop an artifact for BISE/IS researchers as our research's target group. The value we intend to provide is a consistent, clear, and complete synopsis (Schwarz et al. 2007) which helps understand microgrid design options and external influences. Additionally, we want to identify research gaps which the BISE/IS community can address in the future. Besides, practitioners could use the framework to survey the academic SOTA or to structure efforts associated with setting up microgrids and developing this technology's potential.

Through an extensive literature review, we collect previous research studies in order to develop the framework (Schwarz et al. 2007). This is a standard approach to conceptualizing frameworks (Eierman et al. 1995; BarriosO'Neill and Schuitema 2016). We follow the process that vom Brocke et al. (2009) suggest and build on renowned BISE reference models. Furthermore, we conduct a forward/backward search on pre-defined keywords in databases, thus providing an interdisciplinary overview of microgrids: IEEE Xplore and ScienceDirect host articles from connected disciplines (electrical engineering, social sciences, etc.), while AIS e-library serves as a repository for BISE/IS research. We analyze articles from 2002 on, which was when Lasseter et al. (2002) initially described the microgrids concept. Appendix 4 (Electronic Supplementary Material - ESM - available via http://springerlink. com) provides an overview of the keywords, search strings, and relevant SOTA papers. In two already well-researched 
fields, we keep to a forward/backward search based on such current surveys (Hossain et al. 2014; Gamarra and Guerrero 2015). We use a concept matrix (Salipante et al. 1982), presented in Appendix 3 (ESM), to systematize prior research. In a following evaluation, we iteratively improve the framework by validating its completeness, consistency, and clarity based on expert feedback. In line with a framework and a SOTA review's purpose (Schwarz et al. 2007; vom Brocke et al. 2009) and answering RQ 2, we provide directions for further microgrid research with a research agenda.

\section{Development of a Microgrid Framework}

Both hardware and software help bring microgrids to fruition: for instance, devices for sensing and reporting physical conditions assisted by according processing techniques allow for automated control of energy usage (Lasseter et al. 2002). BISE/IS research takes broad perspectives - not solely economic, but also ecological and social - on hardware and software's integrated management (Schmidt et al. 2009). Consequently, a BISE/IS framework suits a managerial view of microgrid design. We therefore build our review's structure by transferring existing frameworks to our case. In Sects. 4.2-4.6, we provide a synopsis of the relevant literature that describes our framework's elements and possible configurations.

\subsection{Framework Transfer and Derivation}

We consider the general frameworks for managing information by Krcmar (2015) and Wollnik (1988) as a universal ground line in BISE/IS research. Both authors define three layers that are relevant for information management (c.f. Appendix 1/2 in ESM): the bottom layer defines the management of the technical infrastructure, namely Information and Communication Technology (ICT). The middle layer focuses on information systems' management (e.g., data structures). The top layer comprises the management of the systems' results (e.g., using information to improve logistics). Krcmar (2015) further describes the overarching management tasks alongside all three layers, such as information technology (IT) controlling (c.f. Appendix 1 in ESM). We adopt these layers as a working assumption.

Like Krcmar (2015)'s framework, an enterprise architecture framework can motivate an operational, systematic approach to a (microgrid) system through its layered structure and its information management roots. The Open Group Architecture Framework (TOGAF) builds on four interrelated domains (Desfray and Raymond 2014; Svee and Zdravkovic 2015): (a) business architecture including strategy, governance, organization, and key processes; information systems architecture encompassing both (b) applications architecture (individual systems, methods, and their interactions) and (c) data architecture (logical and physical data structures); and (d) technical architecture arranging the hardware infrastructure.

All three frameworks contain a layered architecture, which seems suitable to structure the inside of a microgrid. We transfer and adjust these frameworks specifically to microgrids as we derive the design options from literature. Specializing further, we take similar, yet sector-specific existing frameworks into account. Originating from electrical engineering, the Smart Grid Architecture Model (SGAM) categorizes processes and products in the smart grid context. Brandt (2016) also employs SGAM to structure research. The SGAM contains the component, communication, information, function, and business layers, which we combine with other influences below. The German electrical industry uses a layered model that resembles or instantiates the SGAM layers to cluster Industry 4.0 technologies and simplify their complex interrelations: however, this Reference Architectural Model Industrie 4.0 (Hankel 2015) contains no energy-specific indications that we could transfer to the field of microgrids.

Figure 1 shows the final version of the framework after the expert evaluation, which we present in Sect. 5 (for a changelog, see Appendix 7 in ESM). We label the layers in the same way as Wollnik (1988) does, but drop "Management of."

Microgrids contain energy technologies for the generation, storage, distribution, and consumption of energy (Hatziargyriou et al. 2007). Since the three frameworks transferred from information management do not include this perspective, we introduce a fundamental layer: as an equivalent to the management of the technical infrastructure in the aforementioned frameworks, we label this layer I Energy Technology \& Infrastructure. Layer II, Information \& Communication Infrastructure, is located above layer I to convey that basic IT is used to manage a microgrid's energy technology efficiently. We adapt the definition of the transferred layers "Management of Information System" (Krcmar 2015) and "information systems architecture" from TOGAF for layer III. We rename this layer Application Systems, because we perceive the whole microgrid as an information system. We focus on applications for control, planning, and administration in the microgrids context. The top layer "Management of Information" - or, "business architecture" (TOGAF) - considers management tasks by, for example, matching the information demand with the supply (Krcmar 2015). We redefine this layer as layer IV, Governance, because - in contrast to smart grids - various structures of ownership and operation are possible, depending on the objectives (Fridgen et al. 2015; Schwaegerl and Tao 
Fig. 1 Microgrid framework

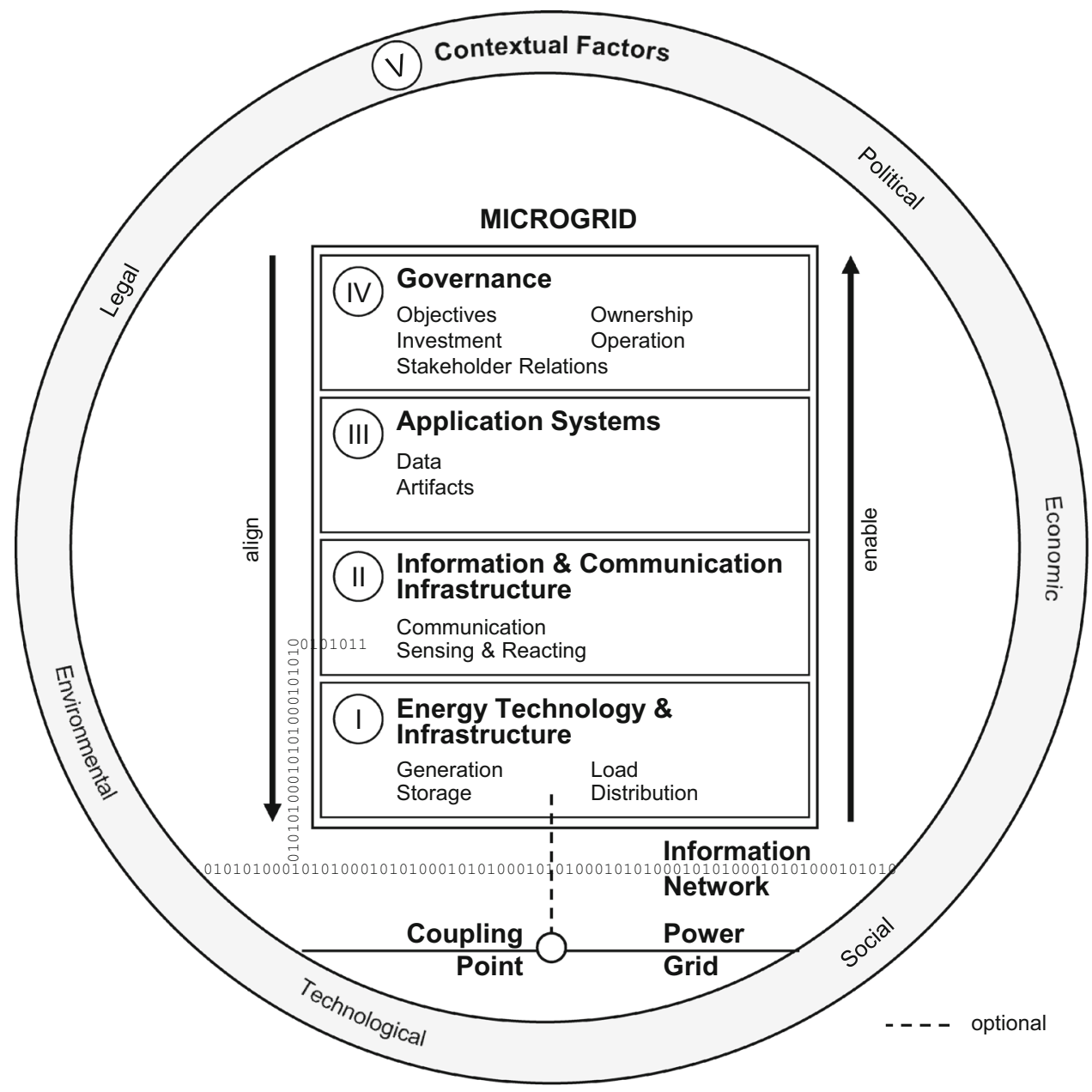

2014b). As in TOGAF, but differing from Krcmar (2015), we incorporate managerial functions (e.g., controlling) in microgrid governance.

Wollnik (1988) emphasizes ICT's upstream supportive function for information systems and information systems' downstream function which requires alignment with ICT (c.f. Appendix 2 in ESM). Likewise, information systems support information usage but align with the latter (Wollnik 1988). Krcmar (2015) uses the terms "enable" to express the supportive role of ICT and information systems, and "align" to convey that requirements from information usage shape the design of information systems and ICT. Accordingly, we maintain this relationship between the layers (arrows in Fig. 1). SGAM has similar interaction between its layers ("interoperability").

Two connections to external systems are characteristic of a microgrid - and not included in the SGAM. First, by employing transmission technology, the Coupling Point of layer I to the main power grid shows that microgrids can be operated in grid-connected mode. Second, layer II connects the microgrid to an information network, allowing for information exchange (e.g., weather forecasts, metering data) and trade on external energy markets (Stadler et al. 2016). Flows from the information network can impact the physical flows in the microgrid: for example, the electricity price information impacts the consumption or the electricity inflow/outflow.

External parameters, such as market characteristics, influence microgrid design (Provance et al. 2011). Our framework incorporates these Contextual Factors. We build upon the established PESTLE analysis, which includes political, economic, social, technological, legal and environmental factors (Zalengera et al. 2014). Defining contextual factors as exogenous, we assume that a single microgrid's design options have no reverse impact. These perspectives match the Reference Model of Open Distributed Processing (RM-ODP), which classifies viewpoints of a system and its environment. In the RM-ODP wording, we will particularly value a business viewpoint, an information viewpoint, and a technology or engineering viewpoint while we develop our framework. 


\subsection{Energy Technology and Infrastructure}

The original microgrid concept (Lasseter et al. 2002) describes a microgrid as a cluster of loads and microsources $(<100 \mathrm{~kW})$ that provides power and heat. Basak et al. (2012) list the Energy Technology \& Infrastructure components along the energy generation-to-loads (mobility, electricity, cooling, heating) process. Consequently, there are instances when such a microgrid for electric energy includes heating or district heating as specific electric loads, while our subject matter does not comprise natural gas or water as an energy form.

As process components, the mechanisms energy conversion, relocation, exchange, and storage ensure grid stability in an intermittency-friendly energy system (Romankiewicz et al. 2014). Fusheng et al. (2015) suggest that microgrids consist of distributed generation, loads, storage, and control devices. All layer components are typically on the same voltage level (Stadler et al. 2016). In our framework, layer I includes the technology required to (1) generate, (2) consume, (3) store, and (4) distribute energy, as well as (5) the coupling point. In a SOTA analysis of pilot sites, Hossain et al. (2014) provide an overview of technologies performing these four functions in microgrid projects.

\section{Generation}

Distributed generation technology can be classified as either fossil or renewable (Hossain et al. 2014). Photovoltaics (PV), wind, micro-hydro, diesel, and gas engines are the frequently used sources in microgrids. Bracco et al. (2016) and Hossain et al. (2014) describe PV as the technology that particularly fits microgrids. Its distributed installation also has a high potential for microgrid applications (Bacha et al. 2015).

2. Load

Lasseter et al. (2002) split loads into critical and noncritical (controllable) ones to indicate their flexibility. In a microgrid, some non-critical loads can be modulated or shifted over time. Demand side management (DSM, Palensky and Dietrich 2011) is an umbrella term for measures that improve the electricity consumption's efficiency. It comprises two major subsets: first, demand response, which describes voluntary load shifting based on price signals, is a vital value stream for microgrids (Stadler et al. 2016). Second, passive DSM, load control in particular, depends on flexible appliances (e.g., dishwashers) or electric vehicles (Allard et al. 2013; Fridgen et al. 2014).

3. Storage

Storage is essential to balance the generation and the load in microgrids. The necessary storage capacity depends on the installed intermittent RES' volume and the given demand side flexibility (Soshinskaya et al. 2014). Batteries, flywheels, and supercapacitors are storage technologies that are usually found in microgrids (Hossain et al. 2014; Soshinskaya et al. 2014). Despite their high costs, batteries are the most popular option. Electric vehicles are another storage option (Mendes et al. 2011) that yields economic benefit by charging strategy optimization (Fridgen et al. 2014).

4. Distribution

The design of power distribution systems can be classified into three categories: radial, mesh, and network distribution (Hossain et al. 2014). Despite having the highest blackout risk, inexpensive radial distribution systems are very often used for microgrid projects (Hossain et al. 2014). Meshed distribution systems are more expensive, but have a bidirectional power flow, which automatically switches the direction if a fault occurs (Hossain et al. 2014). Network distribution has, to date, rarely been used for microgrids.

5. Coupling point

A common coupling point can connect a microgrid to the main grid (Brandt et al. 2014; Jiayi et al. 2008). The distribution system operator (DSO), who is responsible for this main power grid, organizes "the operation, maintenance and development of the distribution network in a given area" (Schwaegerl and Tao 2014b). A DSO is therefore responsible for ensuring local grid stability (ENTSO-E 2015), which might lead to cooperation with microgrid operators in respect of exchanging data and balancing the system. Smart grid development has begun to influence the DSO's role, which will be to provide energy suppliers and consumers with additional services, such as novel demand-side response arrangements (Council of European Energy Regulators 2015; Eurelectric 2016).

\subsection{Information and Communication Infrastructure}

Literature focusses mainly on (1) communication technologies (Gao et al. 2012; Wang et al. 2011) and (2) sensors and actuators (Erol-Kantarci and Mouftah 2011). All are in line with the internet of things architecture, whose perception layer consists of sensors and whose communication layer integrates technologies for sensor data exchange (Jaradat et al. 2015).

1. Communication

Wang et al. (2011) list copper conductors, optical fiber, power line communication, and wireless communication as communication technologies in the smart grid 
context. They stress the importance of wireless technologies, arguing that their monitoring precision is high as is their fault tolerance, they cover large areas, have remote control capability, and are scalable. Every communication network in a microgrid can be wireless: a home area network connects the smart meter and smart devices in a household to each other. Neighborhood and field area networks aggregate the data from all the smart meters across a neighborhood or a community (Tsado et al. 2015). The data are sent to third parties on a wide area network, such as service providers (e.g. system operators) or other microgrids, for mutual coordination (Fadel et al. 2015).

2. Sensing and reacting

To supply data to application systems in microgrids, a sensor and actuator infrastructure is often connected via a wireless sensor network (Erol-Kantarci and Mouftah 2011; Fadel et al. 2015). Tsado et al. (2015) include meters in sensor networks as the middleware for an advanced metering infrastructure. This is in line with Rashed Mohassel et al. (2014), who define a smart meter as a combination of a sensor, a display unit, and a communication module (usually a wireless transceiver). Depuru et al. (2011) extend this definition by including the possibility of operating devices through a smart meter.

\subsection{Application Systems}

Application systems for monitoring and controlling distributed energy resources are widely known as energy management systems (EMS, Su and Wang 2012). EMS use various sources of (1) input data, like information from a utility or on devices in the microgrid, to state and solve optimization problems (Iqbal et al. 2014; Jaradat et al. 2015). Furthermore, EMS integrate methods that we summarize as (2) artifacts, as TOGAF's application and data architectures do.

Markovic et al. (2013) argue that, besides EMS, energy systems require business management systems (BMS) for functions such as billing and consumer relations. Such functions rely on EMS output. An interface, therefore, enables automatized management processes. Information systems developers need to consider behavioral aspects in EMS and BMS user experience design (vom Brocke et al. 2013). For example, Goebel et al. (2014) emphasize the proper presentation of energy data to achieve enduring changes in consumer behavior.

1. Data

Gamarra and Guerrero (2015) mention four major EMS data sources: RES, energy storage, electricity markets, and consumer loads. Olivares et al. (2011) extend the focus beyond real-time data to forecasts of generation, loads, and prices. Su and Wang (2012) regard weather forecasts as another essential source of planning generation and demand. More precisely, Shi et al. (2015) list insolation, wind speed, and temperature as crucial for forecasting generation from RES. Iqbal et al. (2014) provide an overview of the parameters for generic optimization problems in the renewable energies context.

2. Artifacts

Literature reviews of artifacts for renewable energies and microgrids include Iqbal et al. (2014); Liang and Zhuang (2014), as well as Minchala-Avila et al. (2015). EMS can integrate methods for forecasting external market prices (Olivares et al. 2011) and generation from RES (Ahmad Khan et al. 2016), for upfront and ongoing microgrid planning, and for cybersecure control (Liu et al. 2018). Gamarra and Guerrero (2015) distinguish specific planning and operation issues: power generation mix and sizing focus on upfront strategic and tactical problems, for example, which RES to include. Mengash and Brodsky (2017) develop a multi-criteria operation and investment recommender. Most approaches aim at cost reduction. Fridgen et al. (2015) follow a multi-criteria decision approach in their artifact, considering not only economic but also ecological and social objectives. Siting covers continuous strategic and tactical problems that mainly deal with energy distribution and the associated power quality assurance (Gamarra and Guerrero 2015). Scheduling covers operative issues, which constitute the majority of problems in a microgrid. These include the use of resources for generation and storage, trading strategies, and DSM decisions such as load shifting (Gholami et al. 2018; Liu et al. 2017). Specific software helps solve these problems (Ahmad Khan et al. 2016; Mendes et al. 2011).

\subsection{Governance}

Governance describes how to establish policies and continuously monitor their proper implementation. In the microgrid case, layer IV impacts all the other layers. The policies determine the operation, driven by the respective owners' (1) objectives. Microgrids allow to separate (2) ownership, (3) investment, and the (4) operating model. For example, a utility can be the owner of a wind turbine, while the local community funds it, and a third-party service provider operates the microgrid. Consumers would be other external stakeholders. We therefore include (5) stakeholder relations. 
1. Objectives

The literature describes objectives for setting up a microgrid as "benefits," "motives," "opportunities," or "goals." Such objectives are mostly multi-dimensional, while conflicting objectives require trade-offs (Fridgen et al. 2015; Zhang et al. 2012). Overall, microgrid deployment serves the "three main goals of society, those being reliability (both physical and cyber), sustainability, and economic efficiency" (Hossain et al. 2014). In Table 2, we cluster the identified objectives according to sustainability criteria.

2. Ownership

Schwaegerl and Tao (2014b) present three typical microgrid setups: first, in the "DSO monopoly model" (c.f. Sect. 4.2 on the DSO's role), the DSO owns the microgrid while simultaneously taking on the operator and electricity retailer roles. Second, the "liberalized market model" describes split ownership between the DSO, electricity suppliers, municipalities, consumers, and other market participants. Third, single or multiple consumers owning a microgrid characterize the "prosumer consortium model." Adil and Ko (2016) suggest that consumers, communities or municipal utilities own most local energy systems. According to Soshinskaya et al. (2014), DSO monopolies are the most common model in the EU, whereas the liberalized market and prosumer consortium models dominate in other countries. Decisive reasons for this division are regulation and financial aspects.

3. Investment

Attracting investment in a microgrid project is strongly linked to selecting a business model (Sauter and Watson 2007): first, in "plug-and-play" models, the consumer, who is only responsible for the benefits and responsibilities, funds and owns microgeneration. Second, "company-driven" describes a service-based model in which investing energy companies retain ownership and charge for the delivered electricity. Third, "community microgrid" describes socially architected agreements in a specific area (e.g., municipality) with shared responsibility and benefit. In this sense, "energy cooperatives" have come to epitomize households which collectively optimize their energy supply in order to increase their autonomy (Fridgen et al. 2015; Rieger et al. 2016).

4. Operating model

The operating model describes the managerial functions of and responsibility for microgrid operations. According to Krcmar (2015), managerial functions of information systems include strategic alignment, processes, personnel, controlling, and security. Choosing an operating model for a microgrid is closely related to the ownership and investment structure, spanning a continuum of energy company control, contracting, and consumer control (Adil and Ko 2016). A profitdriven service provider cooperating with a utility in electricity trade and dispatch is a potential operating model. In a literature review, Stadler et al. (2016) identify the following potential value streams for microgrids: demand response, electricity export, outage resiliency, and local energy or flexibility markets. The possibility to open up these value streams depends on site-specific conditions such as tariffs (Fridgen et al. 2018).

5. Stakeholder relations

Apart from owners, investors and operator,

Table 2 Objectives in microgrid deployment and operation

\begin{tabular}{ll}
\hline Sustainability criterion & Objective \\
\hline Social & Improve system reliability (Murakami 2014; Schwaegerl and Tao 2014a) \\
& Rural electrification (Mandelli et al. 2016; Millinger et al. 2012) \\
& Urban electrification (Hammer and Hyams 2012) \\
& Raise energy awareness (Schwaegerl and Tao 2014a) \\
& Create research opportunity and jobs (Schwaegerl and Tao 2014a) \\
& Lower electricity bill (Lasseter et al. 2002; McLarty et al. 2015) \\
Economic & Generate revenue through trade on local energy markets, power exports or DSM (Stadler et al. 2016) \\
& Avoid transmission (transport) losses (Schwaegerl and Tao 2014a) \\
Ecological & Improve efficiency (McLarty et al. 2015) \\
& Integrate renewable energies (Ustun et al. 2011; Venkataramanan and Illindala 2002) \\
& Reduce emissions (Schwaegerl and Tao 2014b) \\
& Lower global warming potential (Smith et al. 2015) \\
\end{tabular}


Romankiewicz et al. (2014) identify four major stakeholder groups: local consumers and microgrid members, technology providers and component suppliers, regulated electricity suppliers, and policymakers. Since all pursue individual objectives, stakeholder relations are a challenge and a success factor (Soshinskaya et al. 2014). Adil and Ko (2016) describe decentralized energy systems' socio-technical evolution, in the course of which social dynamics change the consumers' role. Provance et al. (2011) analyze how consumer involvement influences business model choice. Barrios-O'Neill and Schuitema (2016) analyze the media engagement's potential in the sustainable energy sector and develop a strategy to increase consumer engagement through online and interactive communication. Consumer engagement is essential, as microgrid membership cannot be changed as quickly as regular electricity contracts.

\subsection{Contextual Factors}

Contextual factors account for external influences on the microgrid design. We adopt the PESTLE framework, which has been applied to electricity topics before (Zalengera et al. 2014), to analyze these factors. Table 3 provides an overview of the literature addressing contextual factors.

There is a clear regional or national focus when developing microgrids (Tao et al. 2011). Several authors point out that contextual factors differ between countries. Such differences influence, for example, whether microgrids have a positive business case (Basak et al. 2012; Ustun et al. 2011). In the US, microgrids are seen as an option to improve reliability (Hossain et al. 2014). In Europe, the hopes are to absorb the increasing share of renewable energies (Hatziargyriou et al. 2007; Jiayi et al. 2008; Ustun et al. 2011). In developing countries, microgrids are considered a solution for rural electrification (Mandelli et al. 2016; Smith et al. 2015).

Contextual factors can either be drivers of or barriers to microgrid deployment. Soshinskaya et al. (2014) identify such barriers as "technical, regulatory, financial, and stakeholder." Based on a literature review and a case study, they identify the need for further research, especially on stakeholder barriers.

\section{Evaluation}

The framework's usefulness results from its correctness and applicability. As is typical for frameworks (Schwarz et al. 2007), we validate correctness by defining completeness, consistency, and clarity as requirements. Completeness seeks to give an exhaustive answer to our RQ 1 on options for microgrid design. Consistency refers to the sound derivation of the entire framework from a literature review, resulting in accurate content and plausible reasoning. Clarity strives for easy and intuitive understanding, without redundancy or overlap. We draw on expert interviews to ensure that these requirements are met and to complete the indications identified in existing research.

\subsection{Method}

The semi-structured interview is one of the most conventional methods of gathering data in qualitative research (Myers and Newman 2007). Researchers often employ this method to evaluate a framework like ours (Schwarz et al. 2007). As proposed by Myers and Newman (2007), we prepared a semi-structured interview guideline (see Appendix 8 in ESM). The interviews had three parts: one inductive and two deductive.

First, we explained the research topic and objective and posed inductive questions to obtain an understanding of the interviewees' social, organizational, and cultural context (Kaplan and Maxwell 1994). To avoid priming, the definitions we gave did not include parts that we were to discuss later during the interviews (e.g., definitions of microgrid/microgrid design).

Second, we distributed the framework's graphical representation. This part of the interview aimed at evaluating the artifact. According to Kaplan and Maxwell (1994), interviewing potential users is a significant opportunity to improve a system. We tested our framework for the predefined requirements with deductive questions: we checked if it was deemed comprehensive (completeness) and intuitively understandable (clarity), and we asked which dimensions or factors the interviewee would add or assign differently (consistency). For instance, the experts assessed whether the four layers covered all the relevant aspects and the contextual factors were complete. Lastly, we asked the interviewees to instantiate the framework, which meant they had to communicate indications and examples concerning any framework element or influencing microgrid development and design on a holistic level. The interviews were conducted in either English or German and thereafter translated.

The interviews enabled us to iteratively refine the framework: we made continuous adjustments after each expert feedback. Consequently, the interviews' deductive parts differed slightly in order to test the changes to the framework with the next expert. The inductive parts did not differ, except for a slot in which we asked individual questions specific to the interviewee's expertise. All the 
Table 3 Contextual factors influencing microgrid design

\begin{tabular}{|c|c|}
\hline Category & Examples \\
\hline Political (P) & $\begin{array}{l}\text { Policy effects on microgrid operation (Zachar et al. 2015) } \\
\text { Need for economic policy changes (Vahl et al. 2013) }\end{array}$ \\
\hline Economic (E) & $\begin{array}{l}\text { Local energy trading between distributed generation (Tao et al. 2011) } \\
\text { Availability of local energy markets (Stadler et al. 2016) } \\
\text { Electricity market prices (Houwing et al. 2008) } \\
\text { Retail prices (Koirala et al. 2016) } \\
\text { High investment and replacement cost of the microgrid (Soshinskaya et al. 2014) }\end{array}$ \\
\hline Social (S) & $\begin{array}{l}\text { Household load profiles and seasonality (Houwing et al. 2008) } \\
\text { Social acceptance of micro-generation (Wolsink 2012; Wüstenhagen et al. 2007) } \\
\text { Increasing consumer engagement (Koirala et al. 2016) } \\
\text { Conflicting self-interest and trust (Soshinskaya et al. 2014) }\end{array}$ \\
\hline $\begin{array}{l}\text { Technological } \\
\text { (T) }\end{array}$ & $\begin{array}{l}\text { Maturity of technology, e.g. dual-mode operation (Tao et al. 2011) } \\
\text { Development of storage technology (Houwing et al. 2008) } \\
\text { Grid network and capacity (Gamarra and Guerrero 2015) } \\
\text { Power quality and control (Soshinskaya et al. 2014) }\end{array}$ \\
\hline Legal (L) & $\begin{array}{l}\text { Regulation and subsidies (Costa et al. 2008; Gamarra and Guerrero 2015; Tao et al. 2011) } \\
\text { Taxes and surcharges (Koirala et al. 2016) } \\
\text { Interconnection rules with the main grid (Ustun et al. 2011) } \\
\text { Prohibition of bidirectional power flow and local trading (Soshinskaya et al. 2014) }\end{array}$ \\
\hline $\begin{array}{l}\text { Environmental } \\
\text { (E) }\end{array}$ & $\begin{array}{l}\text { Environmental constraints, e.g. area of influence, space availability, RES and other local energy resources, energy density of } \\
\text { the area (Gamarra and Guerrero 2015) } \\
\text { Climate change and emissions (Koirala et al. 2016) }\end{array}$ \\
\hline
\end{tabular}

feedback and the iterative refinement were incorporated into the framework, as depicted in Fig. 1. For a detailed overview of the modifications in the course of the framework's evaluation process, see Appendix 7 (ESM).

\subsection{Interviewee Selection}

In total, we interviewed 18 experts from 15 organizations. We chose the experts carefully on grounds of their experience and current position. When selecting them, we paid attention to their understanding of the information systems involved in microgrids. Based on our own assessment, we conducted five interviews with interviewees with a strong IT background or relevant knowledge. Seven interviews included at least one expert with a medium IT background, and we held only three interviews with experts without an IT background (see Appendix 5 in ESM for an overview). In addition, we covered six stakeholder groups, which gave us rich indications of microgrid technology and its markets. The academic experts (Acad.) are researchers from three disciplines relevant to microgrids: economics, electrical engineering, and BISE/IS research. We only considered researchers with industry experience gained through collaboration projects. The community experts (Com.) are decision makers at municipalities that have installed own generation capacities. The DSO experts have a German and European focus. The start-up experts (StU.) are founders with prior experience of the energy industry. The component supplier experts (Sup.) work for companies that are among the market leaders in smart grid and microgrid technologies. The utility experts (Utl.) have more than 10 years of relevant industry experience.

More information on the interviewees' organizational affiliation is beneficial: we thus disclose the business role of the experts' organizations in the "traditional" electricity market, with the supranational power grid at its core. After all, an increase in microgrids could affect competition in this market and, therefore, potentially influence experts' statements regarding, for instance, microgrids' connection to the main power grid. To identify the appropriate organizational market roles in Appendix 5 (ESM), we refer to the established European electricity market role model (ENTSO-E 2015). Just like the German role model (BDEW 2016), this model depicts the current main grid electricity market. It is therefore only partly transferable to the 
microgrid field. Nonetheless, we can indicate apt market roles for 10 of the 18 experts.

The remaining experts are either academics or affiliated with start-ups and component suppliers. They have their relevant role as innovators in the market for microgrids, furnishing business models, technology, and knowledge, but not in the current main grid electricity market. This way, we simultaneously extend the role logic of those "traditional" models to the market for microgrids, which we consider partly prospective and to which we direct our framework.

Besides the experts' stakeholder group and organizational market role, we indicate their field of expertise since our interview experience taught us that interviewees take different approaches to the microgrid concept, depending on their business (Bus.), engineering (Eng.) or policy (Pol.) background.

\subsection{Analysis}

We used evaluation strategies throughout the interviews to ensure completeness, consistency, and clarity. First, we asked the interviewees whether they deemed the framework complete. Eight interviewees explicitly stated that they did, despite the fact that some may have focused on their respective field of expertise. Second, we tested for consistency by asking the interviewees (or interviewee duos) to explain their understanding of the framework. Nine could fully explain the framework, five focused on parts of it, and one did not explain, instantiating it directly instead. Third, as an indicator of the framework's clarity, we defined the amount of clarifying questions asked. In the early stage, two interviewees stated that the framework was difficult to understand; we also received a higher number of suggestions for improvement. We received eight clarifying questions over the course of the first five interviews, seven questions over the next five interviews, and only two over the last five interviews. This decline indicated the framework's evolution towards higher clarity and comprehensibility.

For instance, the first interviewees advised us to include objectives and stakeholder relations in the governance layer. The later interviews explicitly highlighted the inclusion of these two governance aspects and confirmed their importance. The fact that we included the microgrid's interaction with the power grid via the coupling point in the framework's first refinement, stimulated discussions on the DSO involvement and the potential rulesets for a DSOmicrogrid interaction. The following interviews confirmed that the framework includes the relevant design options and contextual factors. Additionally, the interviewees in later interviews started to spontaneously provide examples of each dimension from their experience when explaining the framework to us. All these experiences suggested that the framework is, to the necessary extent, complete, concise, and clear.

We recorded, transcribed, and stored all the interviews. To derive insights via a simple coding approach, we fitted portions of the transcripts into categories, which we ensured were grounded in the data (Kaplan and Maxwell 1994). Example codes, as seen in Appendix 6 (ESM), were "Regulation is a main influencing factor" or "Layer (I) is most mature." We counted the appearance of statements relating to these codes. Frequently addressed codes pointed towards promising microgrid research directions. If one interview referred to one code several times, we only counted it once to avoid over-weighting specific views.

\subsection{Validity and Reliability of Results}

Two authors analyzed the interview transcripts independently to ensure less biased categorization and to increase the results' internal validity. Additionally, we undertook a simplified pattern matching (Gibbert et al. 2008) to compare the obtained results with our literature review's findings (see Table 4). Triangulation, which refers to adopting multiple perspectives, benefited the construct validity. Specifically, we interviewed 18 experts from six stakeholder groups and with various backgrounds (Myers and Newman 2007) over a short period (Feb-Mar 2016). Still, a larger panel, potentially with additional affiliations like financial services providers, could increase the significance of the opinions.

A general risk of conflicting interests or too narrow an expertise is inherent in the qualitative results gained from expert interviews, which affects the external validity. Further, aggregating the design options on four layers meant generalization, which might oversimplify relationships in some real-world contexts. Contextual factors that experts with a specific German background outlined might not be valid in other regional contexts. Thus, a multicountry comparison of local drivers or barriers might be of value for policymakers and users determining a microgrid's optimal context. To enhance our research's reliability, we documented the steps we performed in a detailed manner, used transcripts, and created a database to store the raw data, as well as the results of the coding exercise (Gibbert et al. 2008). 


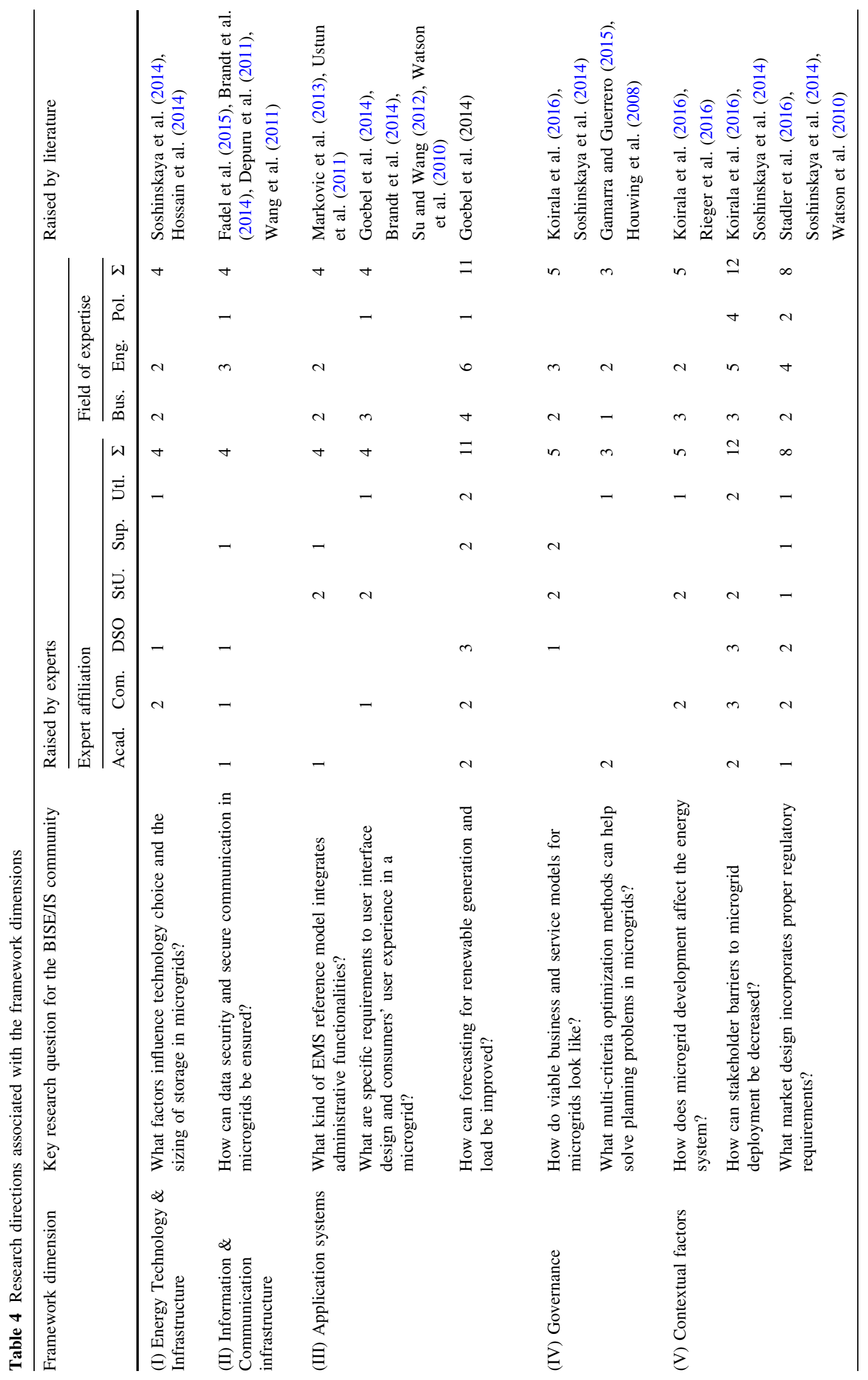




\section{Directions for Microgrid Research in the BISE/IS Community}

Based on the literature and expert interviews, we derive directions for future BISE/IS research (RQ 2). We will outline the questions regarding each of the framework dimensions that researchers could address in the future. We classify a research question as relevant if the literature and a minimum of three experts have referred to it (see Table 4).

1. Energy Technology \& Infrastructure:

The experts and literature agreed that the technology layer is the most mature one. This maturity includes intelligent control of microsources and loads. The most significant research potential lies in storage choice and sizing.

2. Information \& Communication Infrastructure:

An equal number of experts regarded ICT for microgrid applications as either mature or not mature. Information security remains a challenge for a digitized energy system, as pursuing the protection of data and communication is necessary.

3. Application systems:

Information systems are relevant not only for control, but also fulfill administrative functionalities like billing, reporting, and customer relations. Interviewees demanded better integration of EMS and BMS. Additionally, behavioral aspects are crucial: developing appropriate user interfaces plays a significant role in ensuring transparency to residents, which increases the DSM acceptance and fosters energy-efficient behavior. The interviewees desired a specific focus on gamification aspects.

4. Governance:

Viable business models and benefit sharing need to receive more attention if microgrids are to be deployed commercially. Service models for microgrids are closely tied because outsourcing operational tasks is realistic. Furthermore, the involvement of multiple stakeholder groups necessitates global optimization approaches for planning problems.

5. Contextual Factors:

External socio-technical influences currently limit microgrid deployment. The interviews and literature indicated that the stakeholder involvement, particularly in residential microgrids, and the regulatory environment are the main barriers to overcome. Economic efficiency or profitability are prerequisites, except when security of supply can compensate for these prerequisites.

\section{Conclusion}

According to Watson et al. (2010), "we all have a responsibility to mitigate global climate change." Therefore, research on Green IS (vom Brocke et al. 2013) should consider solutions for future energy systems. Based on a systematic SOTA research review, our framework serves to understand what design options and contextual factors one needs to examine in order to choose a suitable microgrid setup. Nonetheless, our approach is subject to limitations and future research could extend this work. Furthermore, BISE/IS studies could catalyze microgrid deployment by addressing the key questions we have presented above.

\subsection{Limitations}

Since the value of a microgrid for a power system depends on contextual factors, this could mean that the benefit might be limited to specific geographic situations. Experts have pointed out that use cases such as rural electrification can be successfully achieved with microgrids, while decentralization may imply a loss of efficiency in a developed power grid, such as that in Europe. We likewise observed differing opinions and an ambivalent discussion during the interviews (c.f. no. 14 and 18 in Appendix 6 in ESM).

When considering the concept of microgrid design in their research, users of our framework could have varying views on its purpose and how it should be employed. By motivating and defining the term from our point of view, we have attempted to provide a full understanding. Space constraint does not allow us to provide a process for understanding the contextual factors, nor support for decisions made when these factors require a trade-off between design options; therefore, both remain subject to further research. The analysis of further literature could strengthen the theoretical foundation for framework development. In addition, technology evolves quickly, which means that we cannot ensure the framework's adaptability to technological changes in years to come.

\subsection{Outlook}

By and large, the interaction of energy technologies with information systems is crucial if microgrids are to benefit power systems. According to the interviewed experts, the technological foundations for setting up and operating microgrids are solid, but the lack of economic and business considerations stalls their implementation. Developing cost-effective and targeted solutions thus requires the integrated perspectives that BISE/IS research can provide. 
We regard the microgrid concept as one technology that could contribute to building a future, more decentralized, energy system, which could help mitigate not only local but also global challenges, such as climate change. In a broader context, this paper aims at sensitizing researchers to reflect on solutions for efficient energy use in general. Action is required; technology and its use are at the core of this action.

Acknowledgements This research was (in part) carried out in the context of the Project Group Business and Information Systems Engineering of the Fraunhofer Institute for Applied Information Technology FIT. The research contribution of two authors was partially supported by the E.ON Stipendienfonds.

Open Access This article is distributed under the terms of the Creative Commons Attribution 4.0 International License (http://crea tivecommons.org/licenses/by/4.0/), which permits unrestricted use, distribution, and reproduction in any medium, provided you give appropriate credit to the original author(s) and the source, provide a link to the Creative Commons license, and indicate if changes were made.

\section{References}

ABB (2015) Microgrids projects portfolio: solutions for fuel savings, lower environmental impact and grid stability. http://bit.ly/ABBmg. Accessed 5 Jan 2017

Adil AM, Ko Y (2016) Socio-technical evolution of decentralized energy systems: a critical review and implications for urban planning and policy. Renew Sustain Energy Rev 57:1025-1037

Ahmad Khan A, Naeem M, Iqbal M, Qaisar S, Anpalagan A (2016) A compendium of optimization objectives, constraints, tools and algorithms for energy management in microgrids. Renew Sustain Energy Rev 58:1664-1683

Allard S, See PC, Molinas M, Fosso OB, Foosnas JA (2013) Electric vehicles charging in a smart microgrid supplied with wind energy. In: IEEE Grenoble Power Tech, pp 1-5

Bacha S, Picault D, Burger B, Etxeberria-Otadui I, Martins J (2015) Photovoltaics in microgrids: an overview of grid integration and energy management aspects. IEEE Ind Electron Mag 9(1):33-46

Barrios-O'Neill D, Schuitema G (2016) Online engagement for sustainable energy projects: a systematic review and framework for integration. Renew Sustain Energy Rev 54:1611-1621

Basak P, Chowdhury S, Halder nee Dey S (2012) A literature review on integration of distributed energy resources in the perspective of control, protection and stability of microgrid. Renew Sustain Energy Rev 16(8):5545-5556

BDEW (2016) Rollenmodell für die Marktkommunikation im deutschen Energiemarkt. https://www.bdew.de/media/docu ments/Awh_20160823_Anwendungshilfe-Rollenmodell-MAKv1.1.pdf. Accessed 10 Dec 2017

BDEW, GIZ, PricewaterhouseCoopers (2016) Delphi Energy Future 2040: study report. http://delphi-energy-future.com/results/. Accessed 10 Dec 2017

Bracco S, Delfino F, Pampararo F, Robba M, Rossi M (2016) A pilot facility for analysis and simulation of smart microgrids feeding smart buildings. Renew Sustain Energy Rev 58:1247-1255

Brandt T (2016) IT solutions for the smart grid. Springer, Wiesbaden

Brandt T, DeForest N, Stadler M, Neumann D (2014) Power systems 2.0: designing an energy information system for microgrid operation. In: Proceedings 35th international conference on information systems, Auckland

Buhl HU, Müller G, Fridgen G, Röglinger M (2012) Business and information systems engineering: a complementary approach to information systems. J Assoc Inf Syst 13(4):236-253

Bundesministerium für Wirtschaft und Energie (2016) Fünfter Monitoring-Bericht zur Energiewende: Die Energie der Zukunft. http://bmwi.de/Redaktion/DE/Publikationen/Energie/fuenftermonitoring-bericht-energie-der-zukunft.html. Accessed 5 Jan 2017

Costa PM, Matos MA, Lopes JAP (2008) Regulation of microgeneration and microgrids. Energy Policy 36(10):3893-3904

Council of European Energy Regulators (2015) The future role of DSOs: a CEER conclusions paper. https://www.ceer.eu/documents/ 104400/-/-/60e13689-9416-047e-873a-2644a74c9640. Accessed 10 Dec 2017

Depuru S, Wang L, Devabhaktuni V (2011) Smart meters for power grid: challenges, issues, advantages and status. Renew Sustain Energy Rev 15(6):2736-2742

Desfray P, Raymond G (2014) Modeling enterprise architecture with TOGAF: a practical guide using UML and BPMN. Morgan Kaufmann, Amsterdam

Eierman MA, Niederman F, Adams C (1995) DSS theory: a model of constructs and relationships. Decis Support Syst 14(1):1-26

ENTSO-E (2015) The harmonised electricity market role model. https://entsoe.eu/Documents/EDI/Library/HRM/2015-Septem ber-Harmonised-role-model-2015-01.pdf. Accessed 5 Jan 2017

Erol-Kantarci M, Mouftah HT (2011) Wireless multimedia sensor and actor networks for the next generation power grid. Ad Hoc Netw 9(4):542-551

Eurelectric (2016) EURELECTRIC's vision about the role of distribution system operators (DSOs). http://www.eurelectric. org/media/258031/dso_vision_final_100216_web-2016-0300092-01-e.pdf. Accessed 20 Dec 2016

Fadel E, Gungor VÇ, Nassef L, Akkari N, Malik MGA, Almasri S, Akyildiz IF (2015) A survey on wireless sensor networks for smart grid. Comput Commun 71:22-33

Fridgen G, Mette P, Thimmel M (2014) The value of information exchange in electric vehicle charging. In: Proceedings 35th international conference on information systems, Auckland

Fridgen G, Gründler A, Rusic M (2015) Energy cooperatives as an application of microgrids: multi-criteria investment decision support. In: Proceedings 36th international conference on information systems, Fort Worth

Fridgen G, Kahlen M, Ketter W, Rieger A, Thimmel M (2018) One rate does not fit all: an empirical analysis of electricity tariffs for residential microgrids. Appl Energy 210:800-814

Fusheng L, Ruisheng L, Fengquan Z (2015) Composition and classification of the microgrid. In: Li F, Li R, Zhou F (eds) Microgrid technology and engineering application. Elsevier, London, pp 11-27

Gamarra C, Guerrero JM (2015) Computational optimization techniques applied to microgrids planning: a review. Renew Sustain Energy Rev 48:413-424

Gao J, Xiao Y, Liu J, Liang W, Chen CLP (2012) A survey of communication/networking in smart grids. Future Gener Comput Syst 28(2):391-404

Gholami R, Watson RT, Hasan H, Molla A, Bjørn-Andersen N (2016) Information systems solutions for environmental sustainability: how can we do more? J Assoc Inf Syst 17(8):521-536

Gholami A, Shekari T, Sun A (2018) An adaptive optimization-based load shedding scheme in microgrids. In: Proceedings 51st Hawaii international conference on system sciences, Waikoloa Village

Gibbert M, Ruigrok W, Wicki B (2008) What passes as a rigorous case study? Strateg Manag J 29(13):1465-1474 
Goebel C, Jacobsen H-A, Razo Vd, Doblander C, Rivera J, Ilg J, Flath C, Schmeck H, Weinhardt C, Pathmaperuma D, Appelrath H-J, Sonnenschein M, Lehnhoff S, Kramer O, Staake T, Fleisch E, Neumann D, Strüker J, Erek K, Zarnekow R, Ziekow H, Lässig J, del Razo V (2014) Energy informatics: current and future research directions. Bus Inf Syst Eng 6(1):25-31

Hammer SA, Hyams MA (2012) Smart energy for cities: decentralized supply resources and their link to the modern grid. In: Zeman F (ed) Metropolitan sustainability. Woodhead, Cambridge, pp $520-555$

Hankel M (2015) The reference architectural model Industrie 4.0 (RAMI 4.0). https://zvei.org/en/press-media/publications/thereference-architectural-model-industrie-40-rami-40/. Accessed 5 Jan 2017

Hatziargyriou ND, Asano H, Iravani R, Marnay C (2007) Microgrids. IEEE Power Energy Mag 5(4):78-94

Hossain E, Kabalci E, Bayindir R, Perez R (2014) Microgrid testbeds around the world: state of art. Energy Convers Manag 86:132-153

Houwing M, Ajah AN, Heijnen PW, Bouwmans I, Herder PM (2008) Uncertainties in the design and operation of distributed energy resources: the case of micro-CHP systems. Energy 33(10):1518-1536

Iqbal M, Azam M, Naeem M, Khwaja AS, Anpalagan A (2014) Optimization classification, algorithms and tools for renewable energy: a review. Renew Sustain Energy Rev 39:640-654

Jaradat M, Jarrah M, Bousselham A, Jararweh Y, Al-Ayyoub M (2015) The internet of energy: smart sensor networks and big data management for smart grid. Procedia Comput Sci 56:592-597

Jiayi H, Chuanwen J, Rong X (2008) A review on distributed energy resources and MicroGrid. Renew Sustain Energy Rev 12(9):2472-2483

Kaplan B, Maxwell JA (1994) Qualitative research methods for evaluating computer systems. In: Anderson JG (ed) Evaluating health care information systems. Sage, Thousand Oaks, pp 30-55

Koirala BP, Koliou E, Friege J, Hakvoort RA, Herder PM (2016) Energetic communities for community energy: a review of key issues and trends shaping integrated community energy systems. Renew Sustain Energy Rev 56:722-744

Krcmar H (2015) Informationsmanagement. Springer, Wiesbaden

Lasseter R, Akhil A, Marnay C, Stephens J, Dagle J, Guttromsom R, Meliopoulous AS, Yinger R, Eto J (2002) Integration of distributed energy resources: the CERTS microgrid concept. https://escholarship.org/uc/item/9w88z7z1. Accessed 30 Oct 2018

Liang H, Zhuang W (2014) Stochastic modeling and optimization in a microgrid: a survey. Energies 7(4):2027-2050

Liu G, Starke M, Xiao B, Zhang X, Tomsovic K (2017) A new distributed optimization for community microgrids scheduling. In: Proceedings 50th Hawaii international conference on system sciences, Waikoloa Village

Liu HJ, Backes M, Macwan R, Valdes A (2018) Coordination of DERs in microgrids with cybersecure resilient decentralized secondary frequency control. In: Proceedings 51th Hawaii international conference on system sciences, Waikoloa Village

Mandelli S, Barbieri J, Mereu R, Colombo E (2016) Off-grid systems for rural electrification in developing countries: definitions, classification and a comprehensive literature review. Renew Sustain Energy Rev 58:1621-1646

Markovic DS, Zivkovic D, Branovic I, Popovic R, Cvetkovic D (2013) Smart power grid and cloud computing. Renew Sustain Energy Rev 24:566-577

Marnay C, Chatzivasileiadis S, Abbey C, Iravani R, Joos G, Lombardi P, Mancarella P, Appen J von (2015) Microgrid evolution roadmap. In: International symposium on smart electric distribution systems and technologies, Vienna, pp 139-144

McLarty D, Civit Sabate C, Brouwer J, Jabbari F (2015) Micro-grid energy dispatch optimization and predictive control algorithms: a UC Irvine case study. Int $\mathrm{J}$ Electr Power Energy Syst 65:179-190

Mendes G, Ioakimidis C, Ferrão P (2011) On the planning and analysis of integrated community energy systems: a review and survey of available tools. Renew Sustain Energy Rev 15(9):4836-4854

Mengash H, Brodsky A (2017) A group recommender for investment in microgrid renewable energy sources. In: Proceedings 50th Hawaii international conference on system sciences, Waikoloa Village

Millinger M, Mårlind T, Ahlgren EO (2012) Evaluation of Indian rural solar electrification: a case study in Chhattisgarh. Energy Sustain Dev 16(4):486-492

Minchala-Avila LI, Garza-Castañón LE, Vargas-Martínez A, Zhang Y (2015) A review of optimal control techniques applied to the energy management and control of microgrids. Procedia Comput Sci 52:780-787

Murakami T (2014) Agent-based simulations of the influence of social policy and neighboring communication on the adoption of grid-connected photovoltaics. Energy Convers Manag $80: 158-164$

Myers MD, Newman M (2007) The qualitative interview in IS research: examining the craft. Inf Organ 17(1):2-26

Olivares DE, Canizares CA, Kazerani M (2011) A centralized optimal energy management system for microgrids. In: IEEE energy society general meeting, pp 1-6

Palensky P, Dietrich D (2011) Demand side management: demand response, intelligent energy systems, and smart loads. IEEE Trans Ind Inform 7(3):381-388

Paraschiv F, Erni D, Pietsch R (2014) The impact of renewable energies on EEX day-ahead electricity prices. Energy Policy 73:196-210

Provance M, Donnelly RG, Carayannis EG (2011) Institutional influences on business model choice by new ventures in the microgenerated energy industry. Energy Policy 39(9):5630-5637

Rashed Mohassel R, Fung A, Mohammadi F, Raahemifar K (2014) A survey on advanced metering infrastructure. Int J Electr Power Energy Syst 63:473-484

Rieger A, Thummert R, Fridgen G, Kahlen M, Ketter W (2016) Estimating the benefits of cooperation in a residential microgrid: a data-driven approach. Appl Energy 180:130-141

Romankiewicz J, Marnay C, Zhou N, Qu M (2014) Lessons from international experience for China's microgrid demonstration program. Energy Policy 67:198-208

Salipante P, Notz W, Bigelow J (1982) A matrix approach to literature reviews. Res Organ Behavior 4:321-348

Sauter R, Watson J (2007) Strategies for the deployment of microgeneration: implications for social acceptance. Energy Policy 35(5):2770-2779

Schmidt N-H, Erek K, Kolbe LM, Zarnekow R (2009) Sustainable information systems management. Bus Inf Syst Eng 1(5):400-402

Schwaegerl C, Tao L (2014a) Quantification of technical, economic, environmental and social benefits of microgrid operation. In: Hatziargyriou ND (ed) Microgrids. Wiley, Chichester, pp 275-313

Schwaegerl C, Tao L (2014b) The microgrids concept. In: Hatziargyriou ND (ed) microgrids. Wiley, Chichester, pp 1-24

Schwarz A, Mehta M, Johnson N, Chin WW (2007) Understanding frameworks and reviews. ACM SIGMIS Database 38(3):29 
Shi X, Damgacioglu H, Celik N (2015) A dynamic data-driven approach for operation planning of microgrids. Procedia Comput Sci 51:2543-2552

Smith C, Burrows J, Scheier E, Young A, Smith J, Young T, Gheewala SH (2015) Comparative life cycle assessment of a Thai island's diesel/PV/wind hybrid microgrid. Renew Energy 80:85-100

Soshinskaya M, Crijns-Graus WHJ, Guerrero JM, Vasquez JC (2014) Microgrids: experiences, barriers and success factors. Renew Sustain Energy Rev 40:659-672

Stadler M, Cardoso G, Mashayekh S, Forget T, DeForest N, Agarwal A, Schönbein A (2016) Value streams in microgrids: a literature review. Appl Energy 162:980-989

Strunz S (2014) The German energy transition as a regime shift. Ecol Econ 100:150-158

Su W, Wang J (2012) Energy management systems in microgrid operations. Electr J 25(8):45-60

Svee E-O, Zdravkovic J (2015) Extending enterprise architectures to capture consumer values: the case of TOGAF. In: Persson A, Stirna J (eds) Advanced information systems engineering workshops. Springer, Cham, pp 221-232

Tao L, Schwaegerl C, Narayanan S, Zhang JH (2011) From laboratory microgrid to real markets: challenges and opportunities. In: Proceedings IEEE 8th international conference of power electronics, pp 264-271

Tsado Y, Lund D, Gamage KAA (2015) Resilient communication for smart grid ubiquitous sensor network: state of the art and prospects for next generation. Comput Commun 71:34-49

Ustun TS, Ozansoy C, Zayegh A (2011) Recent developments in microgrids and example cases around the world-a review. Renew Sustain Energy Rev 15(8):4030-4041

Vahl FP, Rüther R, Casarotto Filho N (2013) The influence of distributed generation penetration levels on energy markets. Energy Policy 62:226-235
Venkataramanan G, Illindala M (2002) Microgrids and sensitive loads. In: IEEE power engineering society winter meeting, pp 315-322

vom Brocke J, Simons A, Niehaves B, Reimer K, Plattfaut R, Cleven A (2009) Reconstructing the giant: on the importance of rigour in documenting the literature search process. In: Proceedings European conference on information systems, Verona

vom Brocke J, Loos P, Seidel S, Watson RT (2013) Green IS: information systems for environmental sustainability. Bus Inf Syst Eng 55(5):295-297

Wang W, Xu Y, Khanna M (2011) A survey on the communication architectures in smart grid. Comput Netw 55(15):3604-3629

Watson RT, Boudreau M-C, Chen AJ (2010) Information systems and environmentally sustainable development: energy informatics and new directions for the IS community. MIS Q 34(1):23-38

Wollnik M (1988) Ein Referenzmodell des Informations-Managements. Inf Manag 3(3):34-43

Wolsink M (2012) The research agenda on social acceptance of distributed generation in smart grids: renewable as common pool resources. Renew Sustain Energy Rev 16(1):822-835

Wüstenhagen R, Wolsink M, Bürer MJ (2007) Social acceptance of renewable energy innovation: an introduction to the concept. Energy Policy 35(5):2683-2691

Zachar M, Trifkovic M, Daoutidis P (2015) Policy effects on microgrid economics, technology selection, and environmental impact. Comput Chem Eng 81:364-375

Zalengera C, Blanchard RE, Eames PC, Juma AM, Chitawo ML, Gondwe KT (2014) Overview of the Malawi energy situation and a PESTLE analysis for sustainable development of renewable energy. Renew Sustain Energy Rev 38:335-347

Zhang X, Sharma R, Yanyi He (2012) Optimal energy management of a rural microgrid system using multi-objective optimization. In: IEEE PES innovative smart grid technologies, pp 1-8 